\title{
MULTIPARENTALIDADE FORÇADA
}

\author{
MULTIPLE PARENTING
}

\author{
${ }^{1}$ Paulo Cezar Dias \\ ${ }^{2}$ Erik Frederico Gramstrup
}

\section{RESUMO}

Com a modificação do conceito de família na história da humanidade, hoje considerado o local de importante valor, visando à realização pessoal de seus membros, em consonância com a Constituição Federal de 1988, consagrou-se os princípios da dignidade da pessoa humana, afetividade, igualdade de filiações e pluralidade de entidades familiares, reconhecendo a parentalidade socioafetiva, fundada no estado de filho afetivo, e a biológica, oriunda dos laços de consanguinidade, surge a multiparentalidade como resposta ao reconhecimento pleno de todas as relações parentais. $\mathrm{O}$ afeto como princípio unificador da família, no entanto, apresenta algumas dificuldades metodológicas. A multiparentalidade forçada também apresenta aporias.

PALAVRAS-CHAVE: Família; Filiação; Parentalidade; Multiparentalidade; Afeto

\begin{abstract}
With the modification of the family concept in human history, now considered the site of important value, aimed at personal fulfillment of its members, in line with the Federal Constitution of 1988 was enshrined in the principles of human dignity, affection, equal affiliations and plurality of family entities, recognizing the socio-affective parenting, founded in the state of emotional child, and biological, originally from consanguinity ties, arises multiple parenting in response to the full recognition of all parental relationships. Affection as the unifying principle of the family, however, presents some methodological difficulties. Forced multiple parenting also features aporias.
\end{abstract}

KEYWORDS: Family; Membership; Parenting; Multiple parenting; Affection

\footnotetext{
1 Doutorando em Direito junto à Faculdade Autônoma de Direito - FADISP, São Paulo, SP, (Brasil). Mestre em "Teoria do Direito e do Estado" pelo Centro Universitário Eurípides de Marília - UNIVEM e Graduado em Direito pela UNIVEM, São Paulo, SP, (Brasil). E-mail: pdias@tjsp.jus.br.

2 Doutor e Mestre em Direito pela Pontifícia Universidade Católica de São Paulo - PUC, São Paulo, SP, (Brasil). Especialista pela Universidade São Judas Tadeu - USJT, São Paulo, SP. Professor do curso de graduação da PUC SP e de Pós-graduação da FADISP. Juiz Federal, (Brasil). E-mail:
} 


\section{INTRODUÇÃO}

O conceito da família contemporânea é muito complexo provocando inúmeras dúvidas e conflitos acerca da paternidade no contexto social, afetivo e principalmente jurídico.

Verifica-se que, a Constituição Federal Brasileira de 1988, ampliou o conceito das famílias, inserindo o princípio de igualdade da filiação, interferindo nas relações familiares, e especificamente nos relacionamentos afetivos, entre pais e filhos, inserindo novos valores à família, e neste bojo, trazendo o princípio efetivo da dignidade humana, fator determinante ao bem estar pessoal.

Este princípio nasceu da necessidade individual de cada indivíduo do grupo familiar, em fazer prevalecer sua realização, seus valores, sua dignidade, fundamentada por sua aceitação no meio social.

A filiação socioafetiva encontra sua fundamentação nos laços afetivos constituídos pelo cotidiano, pelo relacionamento de carinho, companheirismo, dedicação, doação entre pais e filhos.

Sabe-se que, a filiação socioafetiva está cada vez mais fortalecida tanto na sociedade como no mundo jurídico, ponderando a distinção entre pai e genitor, no direito ao reconhecimento da filiação, inclusive no direito registral, tendo-se por pai aquele que desempenha o papel protetor, educador e emocional.

Neste sentido, a paternidade socioafetiva, atualmente não tem previsão legal expressa, mas é reconhecida pelo Direito da Família contemporâneo. O conceito de filiação tem base na relação que existe entre as pessoas em razão dos laços afetivos, e não somente da consanguinidade.

O presente estudo objetiva problematizar a temática da paternidade socioafetiva, em seus mais variados aspectos, através de uma análise do panorama constitucional e da legislação brasileira referente ao tema, estabelecendo o vínculo de filiação, diante da moderna visão do Direito de Família, sem contudo ter a pretensão de esgotar os estudos sobre o tema.

Com o advento da $\mathrm{CF} / 88$ várias mudanças merecem destaque, mas, em especial, a de que a família atual não é mais, exclusivamente, formada pela filiação sanguínea, surgindo uma nova tendência de família, ou seja, a família formada pela filiação afetiva. 


\section{FILIAÇÃO E DO DIREITO DE FAMÍLIA}

A filiação é definida como a relação de parentesco mais próxima existente. A união de uma pessoa aos indivíduos que a geraram, assim como a união entre uma pessoa àquelas que lhe proporcionam carinho, amor, fraternidade ou outros elementos que configuram uma relação de afeto surgindo, nesse caso, a filiação socioafetiva (BONFIM, 2004).

Neste contexto, a concepção tradicional apoiada na filiação biológica não se associa à realidade e com a evolução sofrida pela entidade familiar no decorrer dos tempos. No entanto, a procriação é um fato natural, mas o resultado dela é a filiação que é um fato jurídico com inúmeros efeitos sob o aspecto do direito, assim, a filiação compreende todas as relações, e respectivamente sua constituição, modificação e extinção, que têm como sujeitos os pais com relação aos filhos (VENOSA, 2003).

Segundo Bonfim (2004) até pouco tempo a maternidade era considerada sempre certa - mater semper certa est, o que não ocorria com a paternidade, a qual era sempre incerta, pater semper incertus est. Graças a evolução científica e tecnológica é possível afirmar, com uma alta porcentagem de certeza, a paternidade de determinado individuo.

Apesar de todo este progresso científico e tecnológico, esta comprovação de maternidade ou paternidade do indivíduo não é o suficiente, já que o legislador precisa considerar não apenas fatores que fazem coincidir a verdade jurídica com a verdade biológica, mas também implicações de ordem afetivas e sociológicas que existem na filiação.

Acredita-se que a família existia em período anterior ao surgimento do próprio direito. Desde os primeiros registros sobre a ocupação do Homem no planeta, verifica-se a existência de um agrupamento de pessoas visando o auxílio mútuo e a perpetuação da espécie. Comprova-se tal existência por meio das denominadas pinturas rupestres, nas quais sempre é possível verificar desenhos representando homens e mulheres, adultos e crianças, desempenhando as mais variadas atividades juntos (GAIOTTO FILHO, 2013).

Pode-se dizer que com o passar dos anos, a família dentro do conceito jurídico, foi um dos organismos que mais sofreu alterações, justamente em virtude da mutabilidade natural do homem (GAIOTTO FILHO, 2013).

O modelo de família brasileiro encontra sua origem na família romana que, por sua vez, se estruturou e sofreu influencia no modelo grego (NOGUEIRA, 2007). 
$\mathrm{Na}$ família grega, por exemplo, o homem ao nascer tornava-se automaticamente membro de uma entidade familiar, enquanto que na família romana, no seu período primevo, com o nascimento, o filho se tornava uma propriedade do pai. Ulteriormente o direito romano evoluiu, passando a reconhecer duas espécies de parentesco, o cognatício e o agnatício. A primeira devida do sangue e se assemelha ao parentesco biológico contemporâneo. O vínculo agnatício era puramente civil e derivava da adoção.

O Direito de Família é um dos ramos do direito dos mais dinâmicos, porque seu objeto de estudo, a família, tem por sujeito o ser humano, dinâmico por natureza. Em razão disso, faz-se necessário acompanhar as evoluções ocorridas neste campo, principalmente a legislação, mesmo que às vezes de forma mais lenta (GOBBO, 2002).

Este direito nos últimos anos sofreu e tem sofrido uma adaptação aos novos conceitos oriundos da crescente complexidade da vida moderna, fato que levou o Estado a incluir a família de fato no âmbito de sua proteção.

No Brasil, há uma influência da religião e da moral na estruturação dos vínculos familiares e na adoção das soluções legislativas. No Código Civil Brasileiro, de 1916, somente o casamento representava uma entidade familiar e apenas com tal vínculo tinha proteção do Estado.

Observa-se que o Direito Civil, no período das codificações de primeira geração, foi fundado no casamento e outro tipo de relacionamento não era admitido, nem tampouco outro modelo familiar. O concubinato foi tratado como casamento de segunda classe, este vínculo era marginalizado pela sociedade, em virtude de o casamento ser considerado como algo sagrado e indissolúvel (GONTIJO, 2002).

\footnotetext{
"No Código Civil, de 1916, podemos identificar, seja no que diz respeito aos filhos havidos dessas relações, sempre com o propósito de dificultar-lhes a existência, como por exemplo: o art. 248, IV, que legitima a mulher casada e os herdeiros para reivindicar os bens comuns doados ou transferidos à concubina, num prazo prescricional de dois anos após a dissolução da sociedade conjugal (CC, art. 178, § $\left.7^{\circ}, \mathrm{VI}\right)$; o art. 1.474, que proíbe a instituição de concubina como beneficiária do contrato de seguro de vida" (SANTANA, 2012, p. 5).
}

Todavia, deve-se ressalvar que a jurisprudência caminhou em sentido contrário e por razões práticas muito fortes. Como o casamento religioso não fora reconhecido pela legislação adotada quando da adoção do regime republicano, resultou disso que a maior parte da população, conservando seus hábitos e costumes, não se casava no âmbito civil. Por isso, permanecia em concubinato perante o direito positivo. Os tribunais tiveram naturalmente que reagir a isso, reconhecendo os direitos e deveres decorrentes da formação de uma sociedade 
de fato. Por muito tempo, portanto, o direito das obrigações curou da família não decorrente de casamento. A Constituição de 1934, reconhecendo o efeito civil do casamento religioso, amenizou o problema mas não resolveu totalmente, pois é claro que as uniões informais continuaram a grassar.

Verifica-se que, algumas leis ordinárias posteriores ao Código Civil foram editadas para amparar situações fáticas de evidente injustiça, o que foi, paulatinamente, alterando a rigidez dos dispositivos elencados no Código Civil. Tais leis representaram a estratificação da jurisprudência que, antes mesmo de qualquer iniciativa do legislador nesse sentido, já dera amparo ao antigo concubinato. Sem embargo disso, a palavra "concubino(a)" continuou a ser um termo ambíguo, pois ao mesmo tempo se referia ao que hoje consideramos ser um(a) companheiro(a) e ao que temos como pessoa impedida de contrair união.

A Constituição Federal Brasileira de 1988, ao ser introduzida no mundo jurídico trouxe um novo conceito de direito de família e implantou, como postulados dogmáticos, inúmeros princípios que a própria evolução do meio social, a doutrina e a jurisprudência já adotavam. Como exemplo vê-se o artigo 226 que reconhece outras entidades familiares não instituídas pelo matrimônio. Sendo assim, além da família instituída pelo casamento, passouse a admitir a "união estável" como entidade familiar e o Estado legou proteção também a "família monoparental", comunidade formada por qualquer dos pais e seus descendentes (GOBBO, 2002). Alguns, por conta disso, até mesmo apregoam que a disciplina acadêmica passaria a ser denominada direito "das" famílias, para ilustrar que se admite, no presente regime constitucional, uma variedade não cerrada de tipos e origens familiares. No entanto, não julgamos que seja preciso chegar a tanto. No português brasileiro, usa-se "direito de família", diferentemente de Portugal, em que o costume é grafar "direito da família". A junção da preposição com o artigo passa, mesmo que involuntariamente, a ideia de que há uma única e exclusiva forma de família. Já no uso pátrio não há esse problema. A preposição "de", não associada ao artigo, permite uma indeterminação compatível com a existência de multifárias origens das famílias.

Verifica-se então que, o conceito de família foi alargado no texto constitucional; assim, não só a família regularmente constituída, disciplinada pelas regras rígidas destinadas a reger a instituição do matrimônio é alvo da garantia constitucional.

O que parece um pouco incoerente com o reconhecimento de vários títulos e formas familiares é a inclinação contemporânea de pretender que o regime jurídico seja igual para todas. Julga-se que isso seja um tanto incompatível com a assunção de que as famílias são 
múltiplas e atípicas - pelo menos no sentido de que a tipicidade é aberta. A multiplicidade e a tolerância deveria indicar regimes jurídicos também diversos, alguns mais flexíveis, outros mais rígidos e formais, aos quais cada interessado em constituir família aderiria conforme sua livre manifestação de vontade.

O novo Código Civil introduz, ainda, um novo regime de bens quando do casamento, denominado participação final nos aquestos, que permite que cada um dos cônjuges tenha patrimônio próprio, podendo administrá-lo livremente, cabendo-lhes, quando da dissolução da sociedade conjugal, direito a metade dos bens adquiridos pelo casal durante o matrimônio. Essas são algumas, dentre muitas das inovações que o atual Código Civil trouxe. Para alguns estudiosos do direito, o novo código já nasceu com o seu texto defasado, tendo em vista que certos temas de relevância não foram abordados, como a clonagem, união entre pessoas do mesmo sexo, entre outros. Porém, constata-se que, diante da velocidade das alterações sociais e culturais pelas quais a humanidade vem passando, é quimera tentar atualizar o novo código até a presente data. O que importa é que muitas mudanças significativas foram feitas e que as leis extravagantes estão aí para disciplinar tantos outros temas relevantes que carecem de regulamentação (SANTOS, 2003).

A união estável entre o homem e a mulher como entidade familiar foi reconhecida para efeito de proteção do Estado e com isso, instituiu, a norma programática no sentido de a lei facilitar sua conversão em casamento. Diante disso, a "união estável" adquiriu status legal ao ser incluída na Constituição Federal Brasileira, consoante a Arguição de Descumprimento de Preceito Fundamental - ADPF $132^{3}$.

Segundo Gobbo (2002) o concubinato, ganhou novo nome, união estável, que antes da Constituição Federal não surtia efeitos no âmbito do direito familiar, e sim, no direito obrigacional.

Verifica-se então que, antes da Constituição de 1988, não cabia, no Direito Civil, nenhum modelo familiar que não fosse o fundado no casamento e o concubinato, como já dissemos, era tratado somente no âmbito do direito obrigacional, merecendo o mesmo tratamento dado as sociedades (sociedades de fato).

Constata-se, diante do que foi exposto, que houve uma grande evolução no direito de família, fazendo com que a união estável, saísse do patamar excluído da sociedade de fato,

3 ADPF como ação direita de inconstitucionalidade, com pedido de interpretação conforme do art. 1.723 do Código Civil. Assim sendo, e com base na jurisprudência desta Corte (ADPF-QO n ${ }^{\circ} 72$, Rel. Min. Ellen Gracie, DJ 2.12.2005), conheço da ação como ação direta de inconstitucionalidade, cujo objeto é o art. 1.723 do Código Civil." (ADPF 178, Min. Gilmar Mendes, no exercício da Presidência). Tal transcrição consta no voto do Min. Ayres Britto no julgamento da ADPF 132 e ADI 4277, p. 5. 
sendo considerado a partir dali entidade familiar, produzindo efeitos jurídicos independentemente do direito obrigacional (GOBBO, 2002).

É imprescindível lembrar que a união concubinária não se enquadrava na definição de família, resolvendo-se os prejuízos em conformidade com o Direito das Obrigações e a teoria do enriquecimento sem causa, em analogia à sociedade de fato e no princípio constitucional da dignidade da pessoa humana. Resta, como lembrança deste tempo, que o vigente Código Civil ainda nega efeitos à união resultante de pessoas impedidas para casar, dispositivo esse cuja aplicação encontra muitas dificuldades.

Com o advento da Constituição Federal, a família continua sendo a base da sociedade, mas independe de casamento. Observa-se que a Lei, não quis promover uma equiparação entre casamento e união estável e sim separou a figura do direito das obrigações, onde em que ainda estão as uniões entre pessoas impedidas- sociedades de fato. Quis também facilitar sua conversão em casamento, fato esse que demonstra a preferência do legislador pelo instituto casamento (GOBBO, 2002).

Acredita-se que o desejo dos legisladores era transformar a situação não formal da união estável em matrimônio, por meio de facilidades administrativas e foi concretizada tal vontade em Lei.

Com o escopo de dar cumprimento à norma de hierarquia superior $(\mathrm{CF} / 88)$, foram editadas as Leis $\mathrm{n}^{\circ} \mathrm{s} 8.971$, de 29.12.94 e 9.278, de 10.05.96, a primeira, dispondo a respeito do direito dos companheiros à alimentos e à sucessão e, a segunda, regulando o parágrafo $3^{\circ}$ do artigo 226 da Constituição Federal. Sendo que a última derrogou parcialmente a outra, uma vez que a lei 8.971/94 contempla o direito à sucessão, matéria estranha à Lei n. 9.278/96; segundo alguns autores a lei 8.971/94 continuou em vigor no que tange ao direito sucessório (VIANA, 1999). Isso, até a vigência do Código Civil. Para os tribunais, restou da Lei n. 8.971 o instituto do direito real de habitação, conferido ao (à) companheiro(a) sobrevivente após a extinção da união estável pela morte de algum deles.

A família, nos dias de hoje, não apresenta a mesma configuração da família dos séculos anteriores. A mudança de cultura, de costumes e as exigências da vida contemporânea provocaram alterações, não só no dia a dia, como também em sua posição junto à sociedade.

Desta forma, a família constitui-se em um dos bens mais preciosos da sociedade, no entanto, encontra dificuldade de viver livremente o próprio projeto familiar por causa das exigências das leis e dos códigos pré-estabelecidos. 
Sobretudo, o novo modelo de família é formado por uma relação voltada ao amor, ao afeto e à busca da igualdade e da liberdade entre o casal, em que desaparece a predominância do poder patriarcal e a divisão de papéis, surgindo assim a família constitucionalizada e fraternal.

Quando há simultaneidade da paternidade biológica e socioafetiva na mesma pessoa, há um cenário ideal de paz familiar, porém quando essas paternidades se subdividem entre duas pessoas distintas surge uma série de conflitos a serem resolvidos pelos operadores do direito (ALVES, 2016). 'Resolvidos', ressalvamos, no sentido jurídico do termo, pois permanecem no âmbito psicológico e humano mesmo depois da intervenção dos profissionais.

Assim, há pessoas que tem mais de um pai, seja decorrente de uma relação de padrastia, seja de uma relação homoafetiva em que houve inseminação artificial com material genético de terceiros etc. Com a evolução da família, tais cenários familiares se tornaram a cada dia mais comuns (ALVES, 2016).

Há casos em que, a paternidade biológica e socioafetiva não se materializam na mesma pessoa, e que o magistrado não vislumbra a necessidade de desconstituir nenhum dos vínculos, seja o biológico, seja o socioafetivo, vislumbrando-se a possibilidade de se estabelecer a hipótese denominada pela doutrina de multiparentalidade, ou seja, quando há de forma concomitante a paternidade biológica e socioafetiva, dois pais (ou duas mães) para um mesmo filho. Todavia, sem que uma exclua a outra (ALVES, 2016).

Passaremos agora em revista o que a doutrina tem asseverado sobre a multiparentalidade, para em segundo momento oferecer nossas considerações críticas.

A multiparentalidade - afirma-se - ocorre quando um mesmo indivíduo tem dois pais ou duas mães. O modelo atual de parentalidade, desde os primórdios exigia que o indivíduo fosse registrado por um homem e uma mulher, ou seja, sempre duas pessoas, mas de sexos distintos. Iniciou-se a mudança dessa realidade com o reconhecimento pela doutrina e jurisprudência de que casais homossexuais pudessem adotar, caso em que a criança adotada teria por óbvio duas mães ou dois pais, conforme o caso. Sabe-se que, o desenvolvimento da pessoa está muito além daquela propiciada pelo vínculo genético. A formação de sua personalidade, de seu caráter, sua dignidade, estão diretamente relacionadas ao afeto recebido de seus pais biológicos ou socioafetivo (CASSETTARI, 2015).

Ainda, segundo prestigiosa doutrina, reconhecer a multiparentalidade representa um avanço no direito de família na medida em que respeita os princípios da dignidade da pessoa humana e da afetividade entre os envolvidos. O que identifica a família na atualidade é a 
presença do afeto unindo as pessoas. A multiparentalidade se propõe então a legitimar a maternidade ou paternidade daquele que ama, educa e cria como se pai fosse, sem desconsiderar a mãe ou pai biológico (BATISTA, 2014).

Segundo a doutrina dominante, a ótica do afeto, busca eliminar qualquer dúvida sobre a possibilidade de formação dos grupos familiares, que fogem aos modelos tradicionais. Este olhar mais humano e realista que vê no afeto o elemento formador da família afasta o preconceito e a segregação, trazendo à tona o respeito que se deve ter com as novas formas de família. Temos na prática a aplicação do princípio da igualdade e respeito à diferença.

Nas famílias tentaculares, evidencia-se a essencialidade do afeto na formação do núcleo familiar onde as relações de seus membros são ramificadas, criando uma multiplicidade de vínculos afetivos/familiares. E neste caso, a parentalidade socioafetiva manifesta-se de maneira intensa.

De acordo com a visão predominante, os relacionamentos são baseados socialmente no afeto do que propriamente no interesse patrimonial, contribuindo para a despatrimonialização do Direito da Família. Considerando que as realidades fáticas sociais são o que dão origem ao direito, verifica-se que, a afetividade logo estará presente no ordenamento jurídico brasileiro. No entanto, para alguns doutrinadores, já há o princípio da afetividade, contendo seu amparo na Constituição de 1988 (OLIVEIRA NETO, MEIRELES, 2014).

Enfim, segundo os autores citados, as famílias, da contemporaneidade têm muitos traços em comum, mas nenhum deles, seria mais visível e constante do que o afeto.

Encontramos muitas definições e conceitos para o afeto. Definições na seara do direito, da psicologia, da psiquiatria etc. Mas não se pode furtar à realidade de que o afeto é o laço, ou como dizem, é o que liga um indivíduo ao outro, tornando-o solidário àqueles a quem se afeiçoou.

Fala-se até em princípio da afetividade como emanação do princípio da dignidade humana nas relações familiares. Tamanho avanço no estudo destas relações propicia o reconhecimento deste elemento impalpável, como essencial, quando falamos da família (ROSSOT, 2009).

Para Barros (2011), existe um direito ao afeto e, este "[....] direito ao afeto é a liberdade de afeiçoar-se um indivíduo ao outro". Atribuí ao afeto status de direito individual, cabendo ao Estado garantir seu exercício dentro de limites necessários ao bem de todos. 
Conforme o pensamento que hoje se tornou lugar-comum, a ótica do afeto busca eliminar qualquer dúvida sobre a possibilidade de formação dos grupos familiares, que fogem aos modelos tradicionais. Esse olhar mais humano e realista que vê no afeto o elemento formador da família, afasta o preconceito e a segregação, trazendo à tona o respeito que se deve ter com as novas formas de família. Temos na prática a aplicação do princípio da igualdade e respeito à diferença.

A relevância das relações socioafetivas, no direito de família, tem recebido atenção especial da doutrina. Sobre o tema, vale citar Pereira (2006), para quem:

“Consolida-se a família sócio-afetiva em nossa Doutrina e Jurisprudência, uma vez declarada a convivência familiar e comunitária como Direito Fundamental, a nãodiscriminação de filhos, a co-responsabilidade dos pais quanto ao exercício do poder familiar e o núcleo monoparental reconhecido como entidade familiar".

Com a consagração do afeto a direito fundamental, os mais resistentes viram-se obrigados a rever seus conceitos, inclusive, no tocante à igualdade existente entre a filiação biológica e a socioafetiva. O preconceito e discriminação tiveram de ser definitivamente banidos das relações familiares. Mais uma barreira foi vencida pelo afeto.

Aparentemente, está superada também, a discussão, sobre a origem do afeto: Não tem origem biológica, pois deriva do trato, da convivência, da troca, da reciprocidade e solidariedade que enlaçam àqueles que dele comungam. Quanto a isto não há mais dúvidas, tanto assim que, de acordo com Lôbo (2008):

"O principio da afetividade entrelaça-se com os princípios da convivência familiar e da igualdade entre os cônjuges, companheiros e filhos, que ressaltam a natureza cultural e não exclusivamente biológica da família. A evolução da família "expressa a passagem do fato natural da consangüinidade para o fato cultural da afinidade".

Essa afirmação que, repetimos, é hoje a visão mainstream, proclama-se como a que vem de encontro à realidade, onde famílias se constroem e reconstroem diariamente, em busca de um recomeço calcado na afetividade, existente entre seus membros. O fator biológico, não é elemento essencial nessa reconstrução, o afeto sim.

Diante deste contexto, nota-se a importância da aplicação do princípio da afetividade nas relações familiares, uma vez que ele prioriza a convivência gerada pelos vínculos afetivos.

Não se pode negar que o Direito da Família foi um dos ramos do Direito que mais evoluiu e tentou se adaptar as mudanças sociais. No que tange a paternidade/filiação percebese que ela já não pode ser definida apenas pelos vínculos biológicos, até porque a afetividade tem prevalecido sobre aquele. 
A filiação não é concebida somente pelo elo biológico, pois na maioria das vezes, o que une pais e filhos são os laços do carinho, amor, respeito e cuidados recíprocos.

A paternidade socioafetiva já é uma realidade constitucionalmente reconhecida e que, sem forma de dúvida, visa atender aos interesses da criança e do adolescente. Nisso reside a necessidade de o legislador repensar o texto do Código Civil vigente, a fim de se adequar a realidade das novas famílias brasileiras, onde os laços afetivos são reconhecidos como os mais importantes.

A criança precisa de alguém que cumpra funções maternas ou paternas na vida para que ela se estruture como indivíduo. A família sobrevive independentemente dos vínculos biológicos existentes no seu meio. Deste modo, ela não necessariamente precisa ser natural, mas pode ser cultural. Por isso, as formas de família não podem ser limitadas, visto que na contemporaneidade ela é plural ( PEREIRA, 2006).

Não se deve compreender o papel social do pai e da mãe desvinculado do fator meramente biológico, este conceito deve ser ampliado. Essa função deve ser exercida pensando no bem estar e desenvolvimento dos filhos menores por mais de um pai ou mais de uma mãe simultaneamente, uma vez que há muitos casos de pluralidade de pais que convivem diariamente com a criança e exercem tarefas inerentes ao poder parental. Portanto, é possível que existam dois vínculos materno ou paterno-filiais, em especial nos casos em que um for biológico e o outro socioafetivo, surgindo este antes do reconhecimento da maternidade ou paternidade biológica ou em complementação a estas (ALMEIDA, 2010).

A multiparentalidade é uma alternativa de tutela jurídica para o fenômeno da liberdade de desconstituição familiar e formação de famílias reconstituídas. Assim, caso sejam rompidos os vínculos afetivos ou biológicos, o menor terá mecanismos para garantir seus direitos fundamentais, preservando seu desenvolvimento pleno, gerando os mesmos efeitos do parentesco (BATISTA, 2014).

Verifica-se que, a verdadeira maternidade está baseada na afetividade, não se deve negar o vínculo nos casos em que as ligações afetivas são suficientes para configurar a filiação socioafetiva. Ainda, deve ser ressaltado que a exteriorização da maternidade é mais importante que a verdade biológica, pois compõe o verdadeiro amor que se origina com o nascimento e se aperfeiçoa durante a vida (CASSETARI, 2014).

Alguns chegam mesmo a defender que deva ser alterada a disposição do artigo 1.636 do Código Civil, que preceitua que sobre reconhecer a múltipla filiação parental: 


\begin{abstract}
“Art. 1.636 O pai ou a mãe que contrai novas núpcias, ou estabelece união estável, não perde, quanto aos filhos do relacionamento anterior, os direitos ao poder familiar, exercendo-os sem qualquer interferência do novo cônjuge ou companheiro".
\end{abstract}

Este segmento de doutrina, que critica o artigo citado, interpreta-o no sentido de que nas famílias recompostas não ocorrerá o envolvimento dos filhos de um casamento anterior com o novo cônjuge ou companheiro, o que não corresponderia com a realidade, pois é importante que haja a presença da socioafetividade, que vale ressaltar já vem sendo reconhecida pela jurisprudência como formadora de vínculo parental. Assim, afirmar que o cônjuge ou companheiro de novas núpcias não podem interferir na educação dos filhos oriundos de casamento anterior do consorte representaria um retrocesso, que não pode ser mantido, por isso o artigo deverá ser revisto (TEIXEIRA, 2010). No entanto, não parece que o propósito do dispositivo seja este. Ele apenas estabelece que o poder familiar não é afetado pela dissolução do casamento, como também não o é pela presença de um pai ou mãe "substitutos" (no sentido figurado dessa expressão).

Biológica ou socioafetiva; casamentária ou união estável; monogâmica ou poligâmica; anaparental, monoparental, biparental ou multiparental; desconstituída ou recomposta; real ou virtual; nuclear ou binuclear; os novos diversos arranjos existentes comprovam as profundas mudanças implementadas e a multiplicidade de modelos viáveis que fazem jus a uma nova tutela jurídica adequada à complexidade contemporânea. E, diante dessa ampla diversidade de arranjos familiares existentes, resta quase impossível à legislação elaborar um rol taxativo de regras que enquadram todas essas possibilidades. Assim, os princípios ganham importância fundamental para a compreensão do Direito da Família e da Multiparentalidade (PIRES, 2015).

Acredita-se que, tais princípios possibilitaram ampliar o reconhecimento normativo às configurações familiares existentes e as que viessem a surgir futuramente. São eles que conferem substrato jurídico para a possibilidade de aplicação da multiparentalidade e por isso, de crucial importância para a temática objeto deste artigo.

Na visão de Sarlet (1988) a dignidade é um caráter inerente ao ser humano, não podendo se distanciar dele, sendo uma meta permanente do Estado Democrático de Direito mantê-la, por outro lado, com um pensamento filosófico, a figura da dignidade não esta associada à religião, mas sim a posição social do homem perante a sociedade. Assim, quanto maior o reconhecimento que o indivíduo tivesse perante o meio que vivia maior seria quantificada a sua dignidade (RODRIGUES, 2012). 
O princípio da dignidade da pessoa não representa uma cláusula pétrea, conforme previsão do artigo $60, \S 4^{\circ}$, da Constituição Federal, mas ostenta limite implícito ao poder de reforma constitucional, já que é, ao lado do direito à vida, valor e norma jurídica de maior relevo na arquitetura constitucional pátria.

Por tudo isto, a dignidade da pessoa humana não é vista como um direito, mas de um atributo que todo ser humano possui independentemente de qualquer requisito ou condição, seja ele de nacionalidade, sexo, religião, posição social etc. É considerada como valor constitucional supremo, daí posta no núcleo axiológico da Constituição, protegendo os direitos fundamentais e dando-lhe caráter sistêmico e unitário.

Resumindo, a dignidade independe das circunstâncias concretas, já que inerente a toda e qualquer pessoa humana, pois, até mesmo os maiores criminosos são iguais em dignidade, pois são eles reconhecidos como pessoas, ainda que não se portem de forma igualmente digna nas suas relações com seus semelhantes.

Tais valores refletem a proteção inafastável da pessoa humana e a valorização de aspectos existenciais, na busca pela garantia dos direitos fundamentais, em especial os da personalidade, de cada membro da família. Deles decorrem a despatrimonialização e a repersonalização das relações familiares, portanto, não há dúvidas de que o Estado, ao estabelecer a dignidade da pessoa humana como fundamento da ordem jurídica, conferiu efetiva proteção à família, independentemente de sua configuração, uma vez que busca desenvolver o projeto familiar sobre o afeto, a solidariedade, a confiança, o respeito, a colaboração e a união de seus integrantes. Assim, nota-se que o Direito da Família está intrinsecamente ligado à dignidade humana, de forma a legitimar todas as formas de família, bem como respeitar todos os vínculos afetivos e toda a diversidade de arranjos familiares (PIRES, 2015).

Segundo Pereira (2006) "o princípio da dignidade humana significa para o Direito de Família a consideração e o respeito à autonomia dos sujeitos e à sua liberdade. Significa, em primeira e última análise, uma igual dignidade para todas as entidades familiares", portanto, a Constituição não só abrange a multiparentalidade, como torna inconstitucional qualquer atribuição de tratamento diferenciado às várias formas da família.

Para que sejamos bem entendidos, nosso desejo foi o de apresentar de modo sintético o pensamento dominante sobre o tema. Embora não lhe sejamos totalmente infensos, quer às suas premissas, quer a suas conclusões, apresentamos em seguida nossas preocupações e considerações críticas. 


\section{CONSIDERAÇÕES FINAIS}

Diante das múltiplas facetas familiares, em especial às famílias reconfiguradas, surgiu uma nova modalidade de unidade familiar, a multiparentalidade. Tal arranjo consagra a possibilidade de uma convivência simultânea entre pais/mães afetivos e biológicos, mas, costumeiramente, essas duas formas de parentalidade sempre foram utilizadas por exclusão, auferindo decisões que nem sempre atendem o melhor interesse daquela criança ou adolescente.

Em que pese tal predileção, vêm-se firmando uma tendência jurisprudencial e doutrinária no sentido de que as duas formas de parentalidade devem sem aplicadas de forma complementar, visto que não existe hierarquia entres as duas formas de parentesco. Logo, os princípios constitucionais da dignidade da pessoa humana, da afetividade e do melhor interesse da criança e do adolescente, constituem preceitos de observação obrigatória na análise de cada caso nas relações pluriparentais.

Sendo assim, conclui-se que, a multiparentalidade é uma realidade presente em muitas famílias brasileiras e cientes de que a norma formal vem atender aos clamores da sociedade, não poderia aquela obstacularizar a eficácia legal desta, sob pena de descredibilizar o Judiciário e de não amparar o maior interesse do Direito da Família, qual seja, o de resguardar com dignidade o meio familiar.

No entanto, procuramos aclarar nossas considerações de ordem crítica: (a) o afeto, conquanto seja um elemento da família, não é um conceito unívoco; (b) a doutrina não tem curado de estabelecer com clareza que tipo de afeto daria ensejo ao parentesco, deixando espaço vazio que tem sido preenchido de modo casuístico, quando não arbitrário, pelos tribunais; (c) há sem dúvida um problema de segurança jurídica ligado a essas concepções; (d) a multiparentalidade voluntária representa uma solução para um drama humano do qual o Direito de Família não poderia descurar; já a multiparentalidade imposta ou forçada parece mais criar problemas do que resolvê-los; e não há limites claros sobre onde se pretenda chegar, ou sobre a potencialidade conflitiva dessa noção mal construída.

\section{REFERÊNCIAS}

ALMEIDA, Renata Barbosa de; JÚNIOR, Walsir Edson Rodrigues. Direito Civil: famílias. Rio de Janeiro: Lemen Juris, 2010. p.383. 
ALVES, Sara Antônia Ferreira. A filiação socioafetiva versus a possibilidade de se estabelecer a multiparentalidade. In: Âmbito Jurídico, Rio Grande, XIX, n. 147, abr 2016. Disponível em: <http://ambitojuridico.com.br/site/?n_link=revista_artigos_leitura\&artigo_id=17076>. Acesso em nov.2016.

BARROS, Sérgio Resende. O Direito ao Afeto. 2011. Disponível em: http://www.srbarros.com.br/pt/o-direito-ao-afeto.cont. Acesso: 08/05/2013.

BATISTA, Débora Mayane de Ávila. A Multiparentalidade e seus Efeitos no Âmbito do Direito de Família: análise à luz dos princípios da dignidade da pessoa humana e do melhor interesse da criança, 2014. Disponível em: http://repositorio.uniceub.br/bitstream/235/5572/1/20944199.pdf. Acesso em 24 de jul. 2016.

BONFIM, Thiago José de Souza. UM NOVO RUMO PARA A PATERNIDADE NO CENÁRIO JURÍDICO BRASILEIRO, 2004. Disponível em: <http://intertemas.unitoledo.br/revista/index.php/Juridica/article/view/348>. Acesso em: 10 dez. 2016.

BRASIL. Constituição da República Federativa do Brasil: texto constitucional promulgado em 5 de outubro de 1988, com as alterações adotadas pelas emendas Constitucionais nos 1/1992 a 64/2010, pelo Decreto legislativo no 186/2008 e pelas emendas Constitucionais de Revisão nos 1 a 6/1994. - 32. ed. - Brasília: Câmara dos Deputados, edições Câmara, 2010. 544 p. - (Série textos básicos ; n. 56).

CASSETTARI, Christiano. Multiparentalidade e parentalidade socioafetiva: efeitos jurídicos. São Paulo: Atlas, 2014.

jurídicos. 2. ed. São Paulo: Atlas, 2015.

Multiparentalidade e parentalidadesocioafetiva: efeitos

GAIOTTO FILHO, Washington Luiz. Evolução Histórica Envolvendo o Direito de Família, 2013. Disponível em: JurisWay em 20/02/2013. http://www.jurisway.org.br/v2/dhall.asp?id_dh=10108. Acesso em 20 de novembro de 2016.

GOBBO, Edenilza. A tutela constitucional das entidades familiares não fundadas no matrimônio, 2002. In: Jus Navigandi. Disponível em: <http://www1.jus.com.br/doutrina/texto.asp?id=546>. Acesso em: 30 nov. 2016

GONTIJO, Segismundo. Dos atuais tipos de união e das sociedades decorrentes, 2002. Disponível em: http://www.gontijo-familia.adv.br/escritorio/index/html. Acesso em 20 de nov. 2016.

A família como instituição natural, 2002. Disponível em: http://www.gontijo-familia.adv.br/escritorio/index/html. Acesso em 20 de nov. 2016.

LÔBO, Paulo Luiz Netto,. Socioafetividade no direito de família: a persistente trajetória de um conceito fundamental. Revista brasileira de direito das famílias e sucessões, Porto Alegre: Magister, n. 5, ago./set. 2008. 
NOGUEIRA, Mariana Brasil. A Família: Conceito E Evolução Histórica E Sua Importância, 2007. Disponível em: http://www.pesquisedireito.com/a_familia_conc_evol.htm >. Acesso em: 09 nov. 2016.

OLIVEIRA NETO, José Weidson de e MEIRELES, Ivson Antonio de Sousa. O Princípio da Afetividade no Ordenamento Jurídico Brasileiro ANIMA: Revista Eletrônica do Curso de Direito das Faculdades OPET. Curitiba PR - Brasil. Ano VI, $n^{\circ} 12$, jul-dez/2014. ISSN 2175-7119.

PEREIRA, Rodrigo da Cunha. Direito de família: uma abordagem psicanalítica. 3. ed. Belo Horizonte: Del Rey, 2006.

PIRES, Nadjara das Neves. MultiparentalidadeNovas Perspectivas para os Arranjos Familiares Atuais, 2015. Disponível em: https://repositorio.ufsc.br/bitstream/handle/123456789/158937/TCC\%20-

$\% 20$ Nadjara\%20Pires.pdf? sequence $=1$

RODRIGUES, Lincoln Almeida. Dignidade da Pessoa Humana: do conceito a sua elevação ao status de princípio constitucional. 07/01/2012. Disponível em: http://www.jurisway.org.br/v2/dhall.asp?id_dh=7021. Acesso em 23 jun 2016.

ROSSOT, Rafael Bucco. O Afeto nas Relações Familiares e a Faceta Substancial do Princípio da Convivência Familiar. in. Revista Brasileira de Direito das Famílias e Sucessões. V.9. Porto Alegre: Editora Magister. 2009. p.5.

SANTANA, Fábio Henrique S. de. A União Estável no Brasil: política legislativa até o Novo Código Civil, 2012. Disponível em: www.unifacs.br/revistajuridica/arquivo/edicao_dezembro2002/.../fabio_santana.doc. Acesso em 20 de nov. 2016.

SANTOS, Uélton. Alterações no Direito de Família à luz do Novo Código Civil. In: Âmbito Jurídico, Rio Grande, VI, n. 12, fev 2003. Disponível em: <http://www.ambitojuridico.com.br/site/index.php?n_link=revista_artigos_leitura\&artigo_id=4550>. Acesso em ago 2016.

SARLET, Ingo Wolfgang. Dignidade da pessoa humana e direitos fundamentais na Constituição Federal de 1988. 9. ed. ver. atual. Porto Alegre: Livraria do Advogado Editora, 2011.

TEIXEIRA, Ana Carolina Brochado; RODRIGUES, Renata de Lima. O direito das famílias entre a norma e a realidade. São Paulo: Atlas,2010.

VENOSA, Silvio de Salvo. Direito de família. São Paulo: Atlas, 2003.

VIANA, Marco Aurélio S. Da União Estável. São Paulo, Saraiva, 1999. p 16/17. 